\title{
Mean platelet volume and red cell distribution width levels in initial evaluation of panic disorder
}

This article was published in the following Dove Press journal:

Neuropsychiatric Disease and Treatment

22 September 2016

Number of times this article has been viewed

\author{
Mehmet Asoglu' \\ Mehmet Aslan² \\ Okan Imre' \\ Yuksel Kivrak ${ }^{3}$ \\ Oznur Akil' \\ Emin Savik ${ }^{4}$ \\ Hasan Buyukaslan ${ }^{5}$ \\ Ulker Fedai'
}

Abdurrahman Altındag ${ }^{6}$

'Department of Psychiatry, Faculty of Medicine, Harran University,

Sanliurfa, ${ }^{2}$ Department of Internal

Medicine, Faculty of Medicine, Yuzuncu

Yil University, Van, ${ }^{3}$ Department of Psychiatry, Faculty of Medicine, Kafkas University, Kars, ${ }^{4}$ Department of Clinical Biochemistry, Faculty of Medicine, Harran University, ${ }^{5}$ Department of Emergency Medicine, Faculty of Medicine, Harran University, Sanliurfa, ${ }^{6}$ Department of Psychiatry, Faculty of Medicine, Gaziantep University, Gaziantep, Turkey
Correspondence: Mehmet Asoglu Department of Psychiatry, Harran University, Medical Faculty, Osmanbey Campus, Sanlıurfa 63000, Turkey Tel +904143183109 Fax +904143183192 Email mehmetasoglu@gmail.com
Background: As the relationship between psychological stress and platelet activation has been widely studied in recent years, activated platelets lead to certain biochemical changes, which occur in the brain in patients with mental disorders. However, data relating to the mean platelet volume (MPV) in patients with panic disorder (PD) are both limited and controversial. Herein, we aimed to evaluate, for the first time, the red cell distribution width (RDW) levels combined with MPV levels in patients with PD.

Patients and methods: Between January 2012 and June 2015, data of 30 treatment-naïve patients (16 females, 14 males; mean age: $37 \pm 10$ years; range: $18-59$ years) who were diagnosed with PD and 25 age- and sex-matched healthy volunteers (10 females, 15 males; mean age: $36 \pm 13$ years; range: $18-59$ years) (control group) were retrospectively analyzed. The white blood cell count (WBC), MPV, and RDW levels were measured in both groups.

Results: The mean WBC, MPV, and RDW levels were $9,173.03 \pm 2,400.31 / \mathrm{mm}^{3}, 8.19 \pm 1.13 \mathrm{fl}$, and $12.47 \pm 1.14 \%$, respectively, in the PD group. These values were found to be $7,090.24 \pm 1,032.61$, $6.85 \pm 0.67$, and $11.63 \pm 0.85$, respectively, in the healthy controls. The WBC, MPV, and RDW levels were significantly higher in the patients with $\mathrm{PD}$ compared to the healthy controls ( $P=0.001, P=0.001$, and $P=0.003$, respectively). However, there was no significant difference in the platelet number between the patients with PD and healthy controls $(P>0.05)$.

Conclusion: Our study results are the first to demonstrate that the RDW levels combined with MPV levels significantly increase among patients with PD. We believe that increased RDW and MPV levels can be used as a novel marker for PD.

Keywords: panic disorder, mean platelet volume, red cell distribution width, white blood cell count, platelet number

\section{Introduction}

Panic disorder (PD) is characterized by unexpected recurrent panic attacks that lead to distressing thoughts about future episodes, physical harm, and maladaptive preventive behaviors. ${ }^{1}$ The main characteristic, lack of objective triggers or clues, is helpful to distinguish PD from panic attacks that occur in the context of other psychiatric disorders. A panic attack is defined as a rapid and intense peak of fear presenting with physical impairments, such as accelerated heart rate and excessive sweating, and also cognitive symptoms, including fear of death or losing control. Neuroendocrine changes typically occur during spontaneous panic attacks in these patients. PD is one of the major anxiety disorders to be managed by several genetic factors. ${ }^{2}$

The red cell distribution width (RDW), which is a measure of heterogeneity in the size of circulating red blood cells, is a component of the complete blood count. It is calculated as a percentage of the standard deviation of the red cell volume divided by the mean corpuscular volume. The RDW is commonly used to distinguish iron 
deficiency-induced microcytic anemia and thalassemia, or hemoglobinopathies-related anemia. Increased RDW levels are often caused by impaired erythropoiesis or erythrocyte degradation. ${ }^{3}$ Recent studies have suggested a relationship between increased RDW levels and certain diseases, such as cardiovascular disease (CVD). ${ }^{4}$ Moreover, there is a growing amount of evidence showing that inflammation has a key role in the pathogenesis. The RDW has been also shown to be associated with inflammatory markers in many disorders..$^{5,6}$

Platelets, which are useful to study the intracellular signal transduction, have been extensively used in psychiatry as a peripheral model of the serotonergic system, since they express the 5-hydroxytryptamine (HT) 2A receptors and 5-HT transporters identical to those present in the brain. ${ }^{7,8}$ The uptake of the 5-HT platelet from the plasma is mainly dependent on the 5-HT transporter. Platelets may indicate biochemical alterations happening in the brain under several psychiatric conditions. ${ }^{9}$ Current studies have suggested that platelets may be affected by diverse stressors, including psychological ones. Platelets offer an interesting vantage point for understanding the neurophysiology of various psychiatric disorders. ${ }^{9}$ The mean platelet volume (MPV), which is the measure of the platelet size, is the main determinant of the platelet function. ${ }^{10}$

Although previous studies have investigated the role of MPV levels in PD, many have shown limited and controversial findings. On the other hand, to the best of our knowledge, the RDW levels in PD have not been studied, yet. Therefore, we aimed to evaluate, for the first time, the RDW levels combined with MPV levels in patients with PD.

\section{Patients and methods Study population}

This retrospective study included a total of 30 treatment-naïve patients who were diagnosed with PD (study group) and 25 age- and sex-matched healthy volunteers (control group) between 18 and 59 years of age in the Emergency Medicine Department of Harran University.

The patients with PD were diagnosed by a psychiatrist, according to the Diagnostic and Statistical Manual of Mental Disorders, Fifth Edition criteria. Patients with hypertension, iron deficiency anemia, liver disease, coronary artery or heart valve disease, neurological deficits, pulmonary diseases, endocrine disorders, and urinary tract infections were excluded.

The control group consisted of a total of 25 healthy asymptomatic subjects with a nonspecific medical history and normal physical examination findings. None of the control subjects were on any medication or antioxidant vitamin supplementation, such as vitamins $\mathrm{E}$ and $\mathrm{C}$. They were all free of acute or chronic diseases.

A written informed consent was obtained from each patient. The study protocol was approved by the Ethics Committee of Harran University. The study was conducted in accordance with the principles of the revised 2000 Declaration of Helsinki.

The white blood cell count (WBC), MPV, and RDW levels were measured in both groups using the same devices and kits. Abbott cell-dynruby Cell-Dyn 3200 system device (Abbott Laboratories, Santa Clara, CA, USA) was used for the analysis of complete blood count.

\section{Statistical analysis}

Statistical analysis was performed using SPSS v20.0 software (SPSS Inc., Chicago, IL, USA). The results were expressed as mean \pm standard deviation. The variables were compared using the Student's $t$-test. Qualitative variables were analyzed using the chi-square test. Pearson's correlation analysis was used to analyze the correlation between the variables. A $P$-value of $<0.05$ was considered statistically significant.

\section{Results}

The demographic and clinical data of the study population are shown in Table 1. There were no statistically significant differences in the age and sex between the two groups $(P>0.05)$.

The mean WBC, MPV, and RDW levels were $9,173.03 \pm 2,400.31 / \mathrm{mm}^{3}, 8.19 \pm 1.13 \mathrm{fl}$, and $12.47 \pm 1.14 \%$, respectively, in the study group. These values were found to be $7,090.24 \pm 1,032.61,6.85 \pm 0.67$, and $11.63 \pm 0.85$, respectively, in the healthy controls. The WBC, MPV, and RDW levels were significantly higher in the patients with $\mathrm{PD}$, compared to healthy controls $(P=0.001, P=0.001$, and

Table I Demographic and clinical data of the study and control groups

\begin{tabular}{llll}
\hline Variable & PD $(\mathbf{n}=\mathbf{3 0})$ & Controls $(\mathbf{n}=\mathbf{2 5})$ & P-value \\
\hline Age (years) & $37 \pm 10$ & $36 \pm 13$ & 0.683 \\
Sex (female/male) & $16 / 14$ & $10 / 15$ & 0.324 \\
WBC $\left(/ \mathrm{mm}^{3}\right)$ & $9,173.03 \pm 2,400.31$ & $7,090.24 \pm 1,032.61$ & $\mathbf{0 . 0 0 I}$ \\
RDW $(\%)$ & $12.47 \pm 1.14$ & $11.63 \pm 0.85$ & $\mathbf{0 . 0 0 3}$ \\
MPV (fl) & $8.19 \pm 1.13$ & $6.85 \pm 0.67$ & $\mathbf{0 . 0 0 I}$ \\
Platelet number $\left(/ \mathrm{mm}^{3}\right)$ & $308.17 \pm 79.02$ & $314.42 \pm 80.79$ & 0.773 \\
\hline
\end{tabular}

Notes: Data shown as mean \pm SD. Bold data indicates a statistical significance. Abbreviations: MPV, mean platelet volume; PD, panic disorder; RDW, red cell distribution width; SD, standard deviation; WBC, white blood cell count. 
$P=0.003$, respectively). There was no significant difference in the platelet number between the study and control groups $(P>0.05)$.

\section{Discussion}

This study is the first to demonstrate that patients with PD have significantly higher RDW levels, compared to the healthy controls. In addition, WBC, MPV, and RDW levels were significantly higher in the patient group, compared to the control group.

Several study findings have demonstrated that there is a blood-brain relationship between platelets and the neuronal 5-HT transporter. ${ }^{11}$ Previous studies have shown that is a correlation between platelets and synaptosomal re-uptake. Parallel similar changes can be found in the human blood, brain and cerebrospinal fluid 5-HT levels, following the administration of 5-HT-releasing agents. Furthermore, some authors have suggested an association between depression and an increased risk of vascular events due to the platelet dysfunction. In addition, a meta-analysis confirmed the previous reports, suggesting a correlation between platelet 5-HT uptake and depression. ${ }^{11}$

Depression and anxiety disorders have been suggested to be the main risk factors in the etiology of mortality in CVD. ${ }^{12}$ Anxiety disorders have been demonstrated to increase the risk of myocardial infarction, ${ }^{13}$ and CVD.${ }^{14} \mathrm{PD}$ is one of the most common anxiety disorders. Some authors have also shown an association between PD and CVD. ${ }^{15}$ At pathophysiological levels it has been hypothesized that biological mechanisms may be affected by stress-related conditions, resulting in worsening of cardiovascular functions. Platelet activity increases with the emotional stress, and coronary events such as myocardial infarction can be induced. The MPV has been thought as a determinant marker of the platelet function. Furthermore, increased MPV levels may indicate either increased platelet activation or an increased number of large and hyperaggregated platelets. ${ }^{16}$ Our results showed that this increase may reflect the abnormality of platelets rather than increase in their counts.

Although previous studies have investigated the MPV levels in PD, these results are limited and controversial. Kokacya et $\mathrm{al}^{17}$ found increased MPV levels in the patients with PD, compared to the MPV levels of the control group. However, there were no significant differences in the platelet count between the groups. On the other hand, Gogcegoz Gul et $\mathrm{al}^{10}$ reported reduced MPV levels in the patients with PD, compared to the MPV levels of the control group. In this study, we found significantly higher MPV levels in the patients with PD, compared to the MPV levels of the control group. Therefore, we conclude that an abnormal 5-HT metabolism in platelets may indicate the abnormal function of platelets and increased MPV levels.

Furthermore, anxiety, depression, or disruptive behavior disorder have been shown to be associated with increased catecholamine levels, sympathetic activity, and cortisol secretion. ${ }^{18}$ In a study, Vizioli et $\mathrm{al}^{19}$ reported that increased sympathetic activity could result in increased MPV values. Also, anxiety and depressive disorders have been demonstrated to be associated with increased inflammatory cytokine levels, endothelial dysfunction, and platelet reactivation.

Several studies have investigated MPV levels in psychiatric populations. Some authors reported that platelets were stimulated by the sympathoadrenal activation through 2-adrenoreceptor activation. ${ }^{20}$ The activation of the platelets was shown to induce shape changes and increase MPV levels. ${ }^{21}$ In a study, Ataoglu and Canan reported increased MPV levels in patients with major depression. ${ }^{22}$ The authors also reported that MPV levels were statistically significantly lower compared to the baseline following treatment. In another study, Aschbacher et $\mathrm{al}^{23}$ found a varying degree of alteration in platelets in patients with anxiety disorder. Hausberg et $\mathrm{al}^{24}$ also found an increased sympathetic activity in patients with depression. Moreover, another study reported that MPV levels could be increased due to the increased sympathetic activity. ${ }^{19}$ As a result, the increased MPV levels in patients with depression can be attributed to the increased sympathetic activity. ${ }^{25}$

The RDW is used as a predictor of mortality in the overall population. ${ }^{26}$ There are studies that reported increased RDW levels, despite being within normal reference ranges, were associated with adverse events in patients with heart failure, coronary artery disease, pulmonary hypertension, diabetes mellitus, Alzheimer's disease, and stroke. ${ }^{27}$ However, the pathophysiology remains to be elucidated. On the other hand, to the best of our knowledge, the RDW levels of PD have not been reported, yet. In our study, we found a statistically significant difference in the RDW levels in the study group, compared to the RDW levels of the control group. Our study is the first to investigate the RDW levels in patients with $P D$.

The MPV and RDW levels are simple and cost-effective markers. Our study findings show that the MPV and RDW levels can be used in PD. We recommend these simple and relatively inexpensive methods for the initial examination and prognosis of the disease in these patients. 


\section{Conclusion}

In conclusion, this study is the first to demonstrate that the RDW levels combined with MPV levels significantly increase in patients with PD. We think that the increase in RDW and MPV levels can be attributed to the increase in sympathetic activity. We believe that increase in RDW and MPV levels can be used as a novel marker for PD. However, further prospective clinical studies are required to confirm these findings.

\section{Author contributions}

All authors made substantial contributions to conception and design, acquisition of data, or analysis and interpretation of data; took part in drafting the article or revising it critically for important intellectual content; gave final approval of the version to be published; and agree to be accountable for all aspects of the work.

\section{Disclosure}

The authors report no conflicts of interest in this work.

\section{References}

1. Alpert JS, Thygesen K, Antman E, Bassand JP. Myocardial infarction redefinedea consensus document of the Joint European Society of cardiology/American college of cardiology committee for the redefinition of myocardial infarction. J Am Coll Cardiol. 2000;36;959-969.

2. Kessler RC, Chiu WT, Demler O, Merikangas KR, Walters EE. Prevalence, severity, and comorbidity of 12-month DSM-IV disorders in the national comorbidity survey replication. Arch Gen Psychiatry. 2005;62(6): 617-627.

3. Bessman JD. More on the RDW. Am J Clin Pathol. 1985;84(6):773.

4. Anderson JL, Ronnow BS, Horne BD, et al; intermountain heart collaborative (IHC) study group. Usefulness of a complete blood count-derived risk score to predict incident mortality in patients with suspected cardiovascular disease. Am J Cardiol. 2007;99(2):169-174.

5. Duchnowski P, Szymański P, Orłowska-Baranowska E, Kuśmierczyk M, Hryniewiecki T. Raised red cell distribution width as a prognostic marker in aortic valve replacement surgery. Kardiol Pol. 2016;74(6):547-552.

6. Altiparmak IH, Erkus ME, Kocarslan A, et al. High aortic pulse-wave velocity may be responsible for elevated red blood cell distribution width in overweight and obese people: a community-based, cross-sectional study. Cardiovasc J Afr. 2016;27:1-7.

7. Strawbridge R, Arnone D, Danese A, Papadopoulos A, Herane Vives A, Cleare AJ. Inflammation and clinical response to treatment in depression: a meta-analysis. Eur Neuropsychopharmacol. 2015;25(10):1532-1543.

8. Young JJ, Bruno D, Pomara N. A review of the relationship between proinflammatory cytokines and major depressive disorder. J Affect Disord. 2014;169:15-20.

9. Camacho A, Dimsdale JE. Platelets and psychiatry: lessons learned from old and new studies. Psychosom Med. 2000;62(3):326-336.

Neuropsychiatric Disease and Treatment

\section{Publish your work in this journal}

Neuropsychiatric Disease and Treatment is an international, peerreviewed journal of clinical therapeutics and pharmacology focusing on concise rapid reporting of clinical or pre-clinical studies on a range of neuropsychiatric and neurological disorders. This journal is indexed on PubMed Central, the 'PsycINFO' database and CAS,
10. Gogcegoz Gul I, Eryılmaz G, Ozten E, Hızlı Sayar G. Decreased mean platelet volume in panic disorder. Neuropsychiatr Dis Treat. 2014; 10:1665-1669.

11. Scharinger C, Rabl U, Kasess CH, et al. Platelet serotonin transporter function predicts default-mode network activity. PLoS One. 2014;9(3):e92543.

12. Consensus development conference on antipsychotic drugs and obesity and diabetes. American Diabetes Association; American Psychiatric Association; American Association of Clinical Endocrinologists; North American Association for the Study of Obesity. J Clin Psychiatry. 2004,65(2):267-272.

13. Ayhan SS, Oztürk S, Erdem A, et al. Relation of neutrophil/lymphocyte ratio with the presence and severity of coronary artery ectasia. Turk Kardiyol Dern Ars. 2013;41(3):185-190.

14. Fawzi MH, Fawzi MM, Said NS. C-reactive protein serumlevel in drug-freemale Egyptian patients with schizophrenia. Psychiatry Res. 2011;190(1):91-97.

15. Vanhoutte PM. Platelet-derived serotonin, the endothelium, and cardiovascular disease. J Cardiovasc Pharmacol. 1991;17(Suppl 5):S6-S12.

16. Brown S. Excess mortality of schizophrenia. A meta-analysis. Br J Psychiatry. 1997;171:502-508.

17. Kokacya MH, Copoglu US, Kivrak Y, Ari M, Sahpolat M, Ulutas KT. Increased mean platelet volume in patients with panic disorder. Neuropsychiatr Dis Treat. 2015;11:2629-2633.

18. Yi B, Matzel S, Feuerecker M, et al. The impact of chronic stress burden of 520-d isolation and confinement on the physiological response to subsequent acute stress challenge. Behav Brain Res. 2015;281:111-115.

19. Vizioli L, Muscari S, Muscari A. The relationship of mean platelet volume with the risk and prognosis of cardiovascular diseases. Int $J$ Clin Pract. 2009;63(10):1509-1515.

20. Greisenegger S, Endler G, Hsieh K, Tentschert S, Mannhalter C, Lalouschek W. Is elevated mean platelet volume associated with a worse outcome in patients with acute ischemic cerebrovascular events? Stroke. 2004;35(7):1688-1691.

21. Thompson CB, Eaton KA, Princiotta SM, Rushin CA, Valeri CR. Size dependent platelet subpopulations: relationship of platelet volume to ultrastructure, enzymatic activity, and function. Br J Haematol. 1982; 50(3):509-519.

22. Ataoglu A, Canan F. Mean platelet volume in patients with major depression: effect of escitalopram treatment. J Clin Psychopharmacol. 2009;29(4):368-371.

23. Aschbacher K, Mills PJ, von Känel R, et al. Effects of depressive and anxious symptoms on norepinephrine and platelet $\mathrm{P}$-selectin responses to acute psychological stress among elderly caregivers. Brain Behav Immun. 2008;22(4):493-502.

24. Hausberg M, Hillebrand U, Kisters K. Addressing sympathetic overactivity in major depressive disorder. J Hypertens. 2007;25(10):2004-2005.

25. Canan F, Dikici S, Kutlucan A, et al. Association of mean platelet volume with DSM-IV major depression in a large community-based population: the MELEN study. J Psychiatr Res. 2012;46(3):298-302.

26. Zalawadiya SK, Veeranna V, Panaich SS, Afonso L, Ghali JK. Gender and ethnic differences in red cell distribution width and its association with mortality among low risk healthy United State adults. Am J Cardiol. 2012;109(11):1664-1670.

27. Ozturk ZA, Unal A, Yigiter R, et al. Is increased red cell distribution width (RDW) indicating the inflammation in alzheimer's disease (AD)? Arch Gerontol Geriatr. 2013;56(1):50-54.

and is the official journal of The International Neuropsychiatric Association (INA). The manuscript management system is completely online and includes a very quick and fair peer-review system, which is all easy to use. Visit http://www.dovepress.com/testimonials.php to read real quotes from published authors. 